Rer Per Birsl 5(1): 5-7 (1998)

(1998 Fácultad de Cicnciał Biológicas UNMSM

\title{
UNA NUEVA ESPECIE DE Iragua MELICHAR, 1926 (INSECTA: HOMOPTERA: CICADELLIDAE)
}

\author{
Pedro W. Lozada*
}

\section{RESUNIEN}

Se describe e ilustra una nueva especie de Iragua Melichar, I. chola sp. n., de material procedente de la Zona Reservada de Tambopata, departamento de Madre de Dios, y de Chanchamayo, departamento de Junín, en Perú. El material tipo se encuentra depositado en las colecciones del Museo Nacional de Historia Natural y del Museo de Entomologia de la Universidad Nacional Agraria La Molina, Lima, Perú.

\section{ABSTRACT}

A new species of Iragua Melichar, 1. chola sp. n., from Tambopata Reserved Zone, Madre de Dios department, and Chanchamayo, Junin department, in Peru, is described and illustrated. The type material is deposited in the collections of the Museo Nacional de Historia Natural and the Museo de Entomologia of the Universidad Nacional Agraria La Molina, Lima, Peru.

\section{INTRODUCCION}

Young (1977) revisó el género lragua Melichar, incluyendo diez especies de Centro y Sudamérica. De éstas, reportó cuatro especies para el Penú, diversa (Signoret), montana Young, nubila Young y perplexa Young. Posteriormente, Cavichioli (1991) describió dos especies procedentes de Brasil. El género pertenece al grupo genérico Dicdrocephala. siendo más íntimamente relacionado al género Ladoffa Young. Difiere de éste por la diferente coloración, el mayor tamaño y las diferencias en el patrón de la genitalia masculina.

En este artículo, se describe e ilustra una nueva especie de Iragua, colectada en Chanchamayo y la Zona Reservada de Tambopata (Explorer's Inn). Los depositarios del material tipo son: Museo Nacional de Historia Natural (MUSM). Lima, y Museo de Entomología de la Universidad Nacional Agraria Lid Molina (UNALM), Lima.

\section{IRAGUA CHOLA sp.n.}

Cabeza regularmente pronunciada, margen anterior de la corona obtusamente redondea- do en vista dorsal; Iongitud media de la corona variando de 0.7 a $0.8 x$ el ancho interocular, y de 0.4 a $0.5 x$ el ancho transocular de la cabeza; ocelos más cerca a los ojos que a la línea media de la corona, sobre una línea imaginaria entre los ánģulos oculares anteriores; fóvea media bien marcada; rebordcs antenales no protuberantes, en vista lateral con margen anterior oblícuo y rectilíneo. Clípeo tumido, impresiones musculares levemente marcadas; sutura transclipeal medialmente obsoleta; clipelo siguicndo el portil del clípeo, su ápice redondeado.

Ancho pronotal mayor que el ancho transocular de la cabeza, márgenes laterales convergentes anteriormente, margen posterior ligeramente cóncavo; disco sin esculturas. Escutelo sin estriaciones detrás del surco transverso. Ala antrior con venación apenas perceptible, textura upaca; cuatro celdas apicales, tres celdas anteapicales, la más externa más proximal que las restantes; ápice levemente cóncavo. Pata posterior con fórmula setal femoral 2:1:1.

Coloración: Color de coroná, pronoto, escutelo y alas naranja, dorso anterior usual-

¿Departamento de Encomologia. Museo Nacional de Hinoria Narunal. Aparado 14-0434. Lima 14. Perú. S Mluseo de Entomología. (entro de Comtrol Biológico (ex CiCIU) SENASA. Calle Los Diamantes s/n. Lith. Los Topacios. Vilarte. Lima. Pelú 


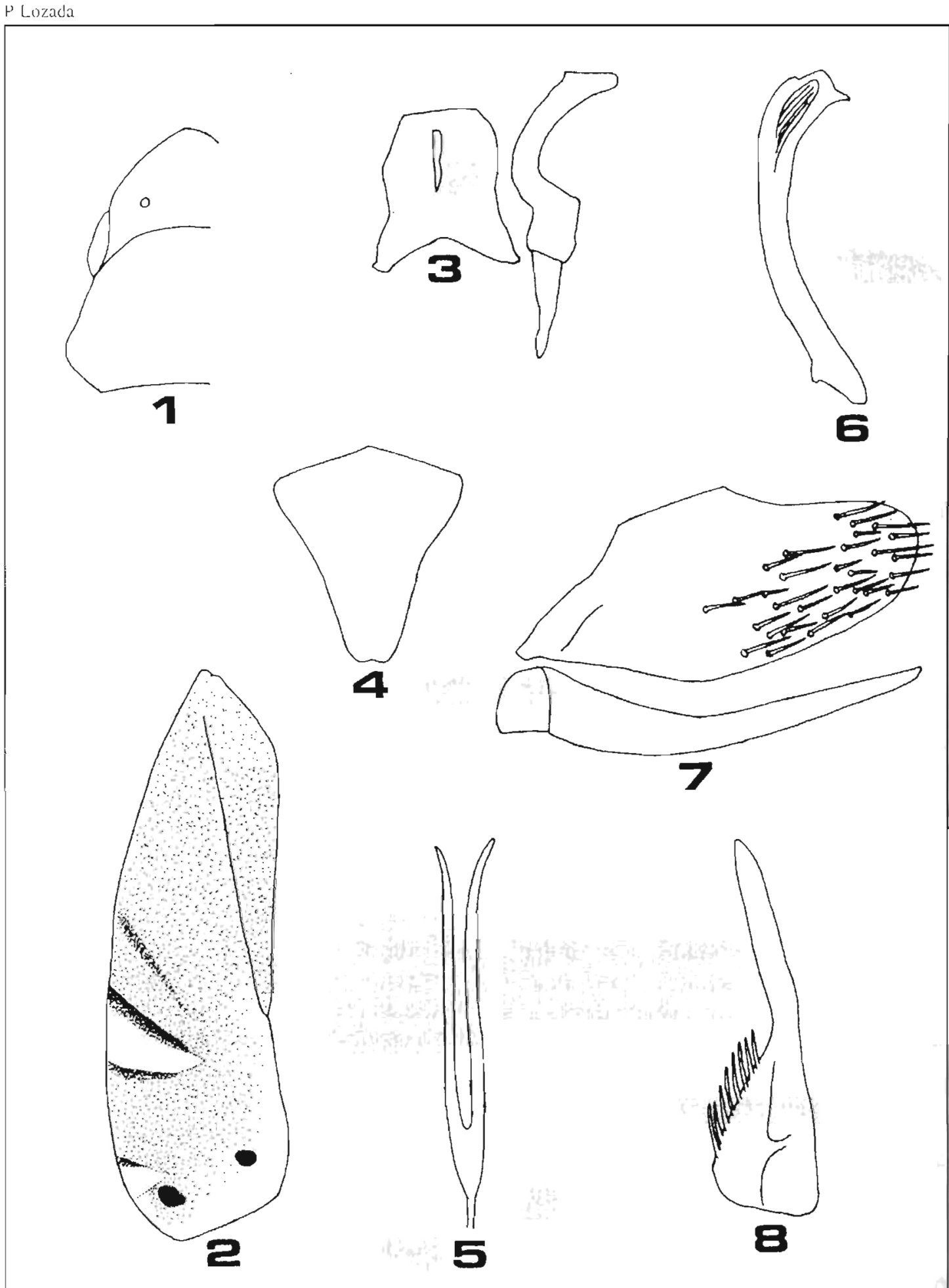

Fig. 1.- Dorso anterior.

Fig. 2.- Ala anterior izquierda

Fig. 3.- Conectivo y estilo izquierdo, vista dorsal

Fig. 4. - Séptimo esterno abdominal de la nembra, vista ventral.
Fig. 5.- Paráfisis, vista ventral.

Fig. 6.- Edeago, vista lateral.

Fig. 7.- Pigófero y placa subgenital izquierda, vista (Pateral).

Fig. 8.- Placa subgenital izquierda, vista ventral. 
mente más pálido, algunas veces cubierto de cerosidad blanca pulverulenta (especímenes de Chanchamayo). Ala anterior con tres franjas transversas oscuras sobre la mitad posterior (Fig. 2), tocando el margen costal, delimitando dos triángulos, el posterior hialino: dos manchas ovaladas negras, una sobre la celda apical externa y la otra sobre la celda apical interna; un pequeño triángulo hialino costal contiguo a la mancha ovalada externa. delimitado en su margen anterior por una franja rojiza adelgazalda hacia su ápice: margen apical y celda apical interna hialinos. Patas color naranja.

\section{Genitalia:}

Macho.- Pigófero regularmente pronunciado (Fig. 7), su margen anterior redondeado, sin procesos; macrosetas circunscritas a la mitad posterior. Placa subgenital triangularalargada (Fig. 8), su longitud casi alcanzando el ápice del pigófero; macroselas uniseriadas sobre la mitad basal del margen externo. Conectivo amplio, ovalado (Fig. 3). Estilo sin lóbulo preapical, sobrepasando aproximadamente en un tercio de su longitud el ápice del conectivo (Fig. 3), ligeramente curvado en dirección distal; ápice ensanchado, truncado, ligeramente quitinizado marginalmente. Paráfisis (Fig. 5) con los rami agudos, largos, ligeramente divergentes apicalmente. Edeago (Fig. 6) alalgado, relativamente delgado. curvado ventralmente, gradualmente ensanchado hacia su ápice, ápice redondeado, con una pequeña espina ápico-ventral.

Hembra. - Séptimo esterno abdominal fuertemente adelgazado posteriormente (Fig. 4), margen posterior redondeado, suavemente hendido en la mitad.

Medidas ( $\mathrm{mm})($ macho/hembra): Longitud total: 10.5.3-11.46/11.2: Longitud media de la corona: 1.00-1.10/1.10; longitud de la corona cercana a los ojos: $0,45-0.50 / 0,50$; longitud del pronoro: 1.60-1.70/1,70: longitud del escutelo: 0,95-1,20/1,05; ancho transocular de la cabeza: 2,00-2,10/2,05; ancho interocular de la cabeza: 1,20-1,40/1,40: ancho del pronolo: 2,30-2,50/2,45; ancho basal del escutelo: 1,50-1,80/1,65; distancia entre los ocelos: $0,70-0,75 / 0,70$; distancia oceloocular: $0,20-0,30 / 0,30$.

Material Tipo: Holotipo macho, PERU, MD, Z.R. Tambopata, 290 m., 26.iii.1987, P. Lozada coll. (MUSM). Paratipos: I macho y I hembra, Chanchamayo [Perú], 16.viii.1985, Arellano coll. (UNALM).

Diagnosis: Iragua chola sp. n. es similar en coloración a /. diversa (Signoret). Difiere de esta especie por la presencia de un triánguto hialino costal anteapical. que no es muy aparente en diversa, por las diferencias en la genitalia masculina, particularmente en la forma del estilo y del edeago, y la diferente conformación del séptimo esterno abdominal de la hembra.

\section{BIBLIOGRAFIA}

CAVICHIOLI. R.R. 1991. Duas noras espécics de Irugua Melichar. 1926. Res: bias. Enr. .35(1): 79-84

YOUNG, D.A. 1977. Taxonomic study of the Cicadellinae. Parr 2. Now World Cicadellini and he genus Cicadella. Tech. Bull. N. Carol agric. Exp. Srat 239: 11135 . 